\title{
Estudi dels requisits indispensables pel bon funciona- ment del treball en grup a la universitat
}

\section{Josep Maria Masjuan* Marina Elias $^{* *}$}

\section{Resum}

En el present article es procedeix a una revisió de diferents elements relacionats amb el treball en grup que aconsegueixen que aquesta metodologia sigui beneficiosa per l'aprenentatge dels estudiants universitaris. En aquest sentit, es dur a terme una revisió de la literatura sobre el tema, alhora que es presenten els resultats d'una recerca quantitativa basada en les dades d'una enquesta obtingudes durant el 2010 sobre un total aproximat de 1000 estudiants de quatre universitats públiques de l'Àrea Metropolitana de Barcelona. Es realitzen anàlisis per mostrar la incidència en el funcionament del treball en grup de cada un dels indicadors que conformen la piràmide de necessitats de Maslow, adaptada al món universitari per Prescott i Simpson (2004). Els resultats mostren com és necessari arribar a certs llindars de qualitat en la implementació d'aquesta metodologia, per tal que aporti aspectes beneficiosos als estudiants universitaris implicats. La reforma de Bolonya (1999), tal i com ha estat implementada no ha aconseguit arribar, en algunes titulacions, a aquest llindar mínim de qualitat.

\section{Paraules clau}

Treball en grup, Procés de Bolonya, aprenentatge, cooperació, estudiants universitaris.

Recepció original: 24 de novembre de 2016

Acceptació: 15 de juny de 2017

Publicació: 19 de gener de 2018

\section{Introducció ${ }^{1}$}

L'entrada de la universitat espanyola a l'Espai Europeu d'Educació Superior (EEES), a partir de la Declaració de Bolonya (1999), ha significat la introducció de canvis en les metodologies pedagògiques per a desenvolupar una docència més centrada en l'estudiant. Els canvis metodològics que s'han anat introduint són dispars segons les universitats, facultats i fins i tot titulacions, però en el context de Catalunya es poden observar tres elements comuns: avaluació contínua, reducció de classes magistrals i treball en grup $^{2}$. El treball en grup és tractat com un element clau perquè és una de les demandes destacables que ha comportat el procés de Bolonya, sobretot a través de les competències transversals.

$\left({ }^{*}\right)$ Professor emèrit de Teoria sociològica i de Sociologia de l'educació, membre fundador del GRET (Grup de Recerca en Educació i Treball). Departament de Sociologia de la UAB. Darrerament s'ha dedicat a la divulgació, per a més informació es pot consultar la pàgina web http://individu-societat.net/

$\left({ }^{* *}\right)$ Professora agregada del Departament de Sociologia de la UB i membre del GRET (Grup de Recerca en Educació i Treball) de la UAB. Recerca centrada en l'anàlisi de les desigualtats educatives en les transicions dels joves, en l'accés a la universitat i les diferents formes de viure el període universitari, incloent aquí l'anàlisi de canvis pedagògics introduïts a les aules. Adreça electrònica: marinaelias@ub.edu

(1) El present article ha estat elaborat en el marc de la recerca titulada «Los estudiantes ante la nueva reforma universitaria» que forma part del «Plan Nacional de investigación científica, desarrollo e investigación tecnológica» (CSO2008-02812) finançada pel Ministerio de Ciencia e Innovación.

(2) És evident que hi ha diferències entre titulacions respecte de la implementació del Procés de Bolonya i els efectes que generen en l'aprenentatge dels estudiants. 
Aquest article forma part d'una recerca més àmplia en curs sobre els factors que influeixen en l'aprenentatge dels estudiants universitaris tenint en compte tant els condicionants de la institució (qualitat de l'ensenyament, recursos, inclusió a la universitat) com les capacitats i actituds dels individus davant de la titulació escollida.

La recerca contempla dues parts ben diferenciades. En la primera, basada en la metodologia de recerca qualitativa, s'ha entrevistat els responsables de les titulacions, el professorat de dues matèries i vuit estudiants de cada una de les 10 titulacions escollides en quatre universitats (UAB, UB, UPF i UPV) de l'àrea de Barcelona. En la segona part, de caràcter quantitatiu s'ha realitzat una enquesta per qüestionari a una mostra de prop de 1000 estudiants $^{3}$ de les titulacions escollides quan estan a la meitat del pla d'estudis. Aquest qüestionari s'ha elaborat a partir de la informació recollida en la primera part i les aportacions teòriques d'altres recerques entorn a aquest tema (Troiano et al, 2012).

L'objectiu d'aquest article, que pertany a la segona part de la recerca, quantitativa, és descriure al funcionament dels grups de treball i la percepció que tenen els estudiants d'aquest procediment de cara al seu aprenentatge. Principalment, se centra en les dificultats o barreres de caràcter institucional que troben els estudiants a l'hora de posar en pràctica el treball de grup com un procediment d'aprenentatge.

Així doncs, en primer lloc, es presentarà la fonamentació teòrica de la recerca i el model d'anàlisi utilitzat. En segon lloc, s'analitzaran les dades pertinents en relació a la pràctica del treball de grup i s'apuntaran de manera hipotètica els possibles mecanismes explicatius. Per últim, es resumiran les principals conclusions dels resultats assolits.

\section{L'estat de la qüestió sobre el treball de grup}

\section{El treball de grup com a mètode docent}

En el terreny de l'aplicació pràctica, és de sobres conegut que el treball de grup com a eina d'ensenyament/aprenentatge en l'ensenyament previ universitari ha estat present des dels inicis de la pedagogia activa a finals del segle XIX, a partir de les aportacions d'autors clàssics com Dewey, Decroly i Freinet. En el món de la recerca psicològica les aportacions de Kurt Lewin (1952) han estat molt rellevants.

A Catalunya, Darder i Franch (1991) han fet una aportació interessant en la qual inclouen en l'anàlisi també els aspectes de caràcter sociològic. Aquests autors es plantegen tant els aspectes estàtics com els dinàmics dels grups classe en l'escola primària i secundària. El model que plantegen i les recerques que aporten tenen en compte el marc institucional de l'escola i les característiques dels estudiants en edat i classe social. En l'anàlisi de les dinàmiques de grup consideren les relacions afectives, les relacions de poder/autoritat, els rols funcionals, i l'actuació dels estudiants en relació als objectius del grup.

Entre els autors de referència actuals sobre el treball en grup com a mètode docent s'han de citar als germans David W. i Roger Johnson (1985), els quals a partir de diferents recerques han fet un esforç de definir en què consisteix el treball cooperatiu en

(3) Humanitats (58), Traducció i Interpretació (100), Empresarials (127), Educació Social (81), Infermeria (136), Farmàcia (78), Biologia Humana (48), Química (95), Arquitectura (77), E.T. en Telecomunicacions (51). Total 851 estudiants. 
l'ensenyament d'estudiants adults i quines són les condicions del seu èxit. Al seu torn, han produït materials diversos per tal de facilitar el seu ús com a recurs didàctic. Segons aquests autors hi ha quatre eixos bàsics del treball cooperatiu: a) interdependència positiva: consciència que l'èxit de cadascú depèn de l'èxit dels altres; b) interacció cara a cara: cada estudiant ha de comunicar els seus resultats i els companys I'han de poder avaluar. Quantes més decisions calgui prendre, més interaccions hi haurà; c) responsabilitat individual: cada estudiant és responsable d'una part de la tasca del grup; d) destreses socials: comunicació, presa de decisions i valoració mútua.

En aquest sentit, també cal esmentar dues troballes importants en relació al funcionament dels treballs en grup. En primer lloc, Wilkinson i altres (1999) arriben a la conclusió que els treballs de grup són una via molt efectiva per a fomentar les interaccions entre companys de classe, la qual cosa té efectes positius en l'aprenentatge dels estudiants i en el seu desenvolupament afectiu i social. En segon lloc, partint de la piriàmide de necessitats descrita per Maslow (1954), que sustenta que perquè el treball de grup funcioni adequadament cal que tant les condicions de manteniment o higièniques (necessitats bàsiques i seguretat) com els motivadors (accions institucionals que incentiven la inclusió, l'ego-status i l'autonomia dels estudiants), tinguin un nivell suficient (Herzberg, 1966; Prescott i Simpson, 2004; Creyer i Elton, 1990; Villar i Font, 2007; Masjuan i Troiano, 2009). Aquest darrer aspecte serà desenvolupat més àmpliament a l'apartat sobre el model d'anàlisi i els resultats obtinguts en la recerca.

\section{Els mecanismes explicatius de la cooperació}

Les ciències socials es mouen des dels seus inicis a partir de dos paradigmes relativament diferents. Un d'aquests paradigmes és més holista, i posa l'èmfasi en la importància de la cultura, la socialització i els rols socials, -més present entre els antropòlegs i sociòlegs-. L'altre és més individualista, i posa l'èmfasi en l'individu i les seves decisions en un context d'oportunitats determinat -més present entre els economistes i els professionals de la ciència política- (Masjuan, 2017; Lizón, 2016).

Les interaccions entre ambdós són diverses però acostumen a tenir un tret en comú: l'oblit del component biològic de la conducta humana, aspecte que els porta o bé a donar només importància a la socialització o bé a simplificar les motivacions humanes tot reduint-les a l'egoisme i a la racionalitat instrumental.

El punt de partida d'aquesta recerca se situa més en la corrent individualista, en el sentit de no quedar-se, a l'hora de voler explicar la conducta en un procés circular que tot ho atribueix a la socialització, però, a més a més, intenta incorporar elements relacionats amb la història evolutiva de l'espècie humana (Masjuan i Elias, 2012; Masjuan, 2017).

L'economista Simon (2006) amb la seva aportació sobre la racionalitat limitada i P. Blau (1964), amb el seu intent d'ampliar les motivacions humanes i no reduir-les a l'egoisme primari, han estat predecessors rellevants d'aquest enfocament.

Al referir-se als grups, Blau ressalta que: a) les associacions humanes estan arrelades en processos psicològics bàsics com ara els sentiments d'atracció mútua (expressius) i les motivacions per assolir diversos tipus de recompenses (instrumentals); b) la recompensa principal és l'aprovació social d'aquells que consideren importants per ells; c) l'atracció social promou la preocupació per impressionar els altres i intercanviar amb 
ells; d) els individus actuen normalment per egoisme en tant que esperen recompenses socials, encara que en alguns casos pot no ser així; e) tendeixen a buscar la reciprocitat (equilibri) per eliminar la tensió d'estar en deute amb els altres; però tenen l'aspiració de generar desequilibris al seu favor, per exemple fent que els altres els hi deguin favors, ja que així se senten superiors i tenen més estatus; f) els líders necessiten una certa ascendència sobre els altres per poder coordinar però el procés de guanyar ascendència sobre els altres està en contradicció amb el de guanyar la seva aprovació. Dintre de la tradició de les ciències socials, altres autors han fet bones contribucions en aquesta mateixa direcció com Elster (2007), Scharpf (1997), Hanley et al. (2008) i Gigerenzer (2008).

\section{El model d'anàlisi de la recerca}

L'anàlisi consisteix en el contrast de les percepcions dels estudiants sobre les oportunitats que els hi dóna el treball de grup com a metodologia docent de cara a la millora del seu aprenentatge i, en darrer terme, el resultat de les avaluacions. La figura 1 mostra les necessitats segons la piràmide de Maslow reelaborada per Herzberg, adaptada al món universitari per Prescott i Simpson (2004).

Per tant, els factors bàsics són elements necessaris, requisits mínims, per a poder desenvolupar els factors motivadors de l'aprenentatge, els quals tenen a veure amb les necessitats socials d'inclusió, el reconeixement social que genera autoestima i la realització personal. El punt que té en compte la inclusió es pot relacionar amb l'explicació dels mecanismes de cooperació, tot lligant les aportacions de Blau i les de Pascarella, Terennzini i Tinto, entre d'altres, que ressalten la importància de la integració per a la millora de l'aprenentatge.

En la tercera columna, hi ha els aspectes més importants, extrets de la teoria i de recerques anteriors, que si funcionessin adequadament haurien de ser oportunitats per assolir uns bons resultats educatius. Aquests elements són els indicadors que analitzarem al llarg de l'article per veure en el context concret si les necessitats bàsiques arriben a un llindar mínim que permeten contribuir a la inclusió social i l'autoreconeixement.

L'objectiu del present article serà, doncs, analitzar el pes de cada un d'aquests indicadors en el funcionament del treball en grup en els contextos analitzats.

Figura 1. Condicions de manteniment i motivadors de tipus general i en concret referits al treball de grup

\begin{tabular}{|c|c|c|c|}
\hline \multirow{3}{*}{ 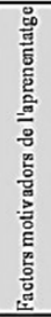 } & $\begin{array}{c}\text { REALITZACIÓ } \\
\text { PERSONAL } \\
\end{array}$ & Apren entatge ind ependent & $\begin{array}{l}\text { Percepció del progrés en les habilitats i els coneixements } \\
\text { Identificació amb la universitat }\end{array}$ \\
\hline & EGO STATUS & $\begin{array}{c}\text { Avaluació } \\
\text { Retorns sobre els resultats }\end{array}$ & $\begin{array}{l}\text { Millora en els notes } \\
\text { Estratègies d'avaluació justes } \\
\text { Feedoack del professorat sobre els encerts i errors dels estudiants }\end{array}$ \\
\hline & $\begin{array}{l}\text { INCLUSIÓ } \\
\text { SOCIAL }\end{array}$ & Inclusió social i acadèmica & $\begin{array}{l}\text { Divisió del treball eficaç per assolir els objectius del grup } \\
\text { Lideratge adequat per part đo un estudiant del grup } \\
\text { Estabilitat del grup i confiança reciproca } \\
\text { Contacte professors i estudiants (empatia) } \\
\text { Mecanismes per al control dels aprofitats }\end{array}$ \\
\hline \multirow{2}{*}{ 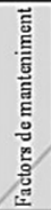 } & SEGURETAT & $\begin{array}{l}\text { Informació clara sobre els } \\
\text { mecanismes de documentació } \\
\text { i avaluació }\end{array}$ & \multirow{2}{*}{$\begin{array}{l}\text { Mida del grup ade quada } \\
\text { Orientació per part del profes sarat } \\
\text { Criteris clars đavaluació grupals i incrividuals } \\
\text { Adequació de la proposta de treball per fer-lo en grup } \\
\text { Manca de temps deguda a la pressió de la feina } \\
\text { Dificultat de reunir-se amb els companys del grup }\end{array}$} \\
\hline & $\begin{array}{l}\text { NECESSITATS } \\
\text { BÄSIQUES }\end{array}$ & $\begin{array}{l}\text { Horaris } \\
\text { Calendari }\end{array}$ & \\
\hline
\end{tabular}

Font: Elaboració pròpia a partir de Prescott i Simpson (2004) i Villar i Font (2007) 


\section{Resultats sobre les condicions de manteniment: Necessitats bàsiques i seguretat ${ }^{4}$}

De cara a proporcionar unes dades generals sobre el treball de grup, que puguin orientar el seguiment de tota l'anàlisi s'ha escollit la taula 1 on es mostra la relació entre la freqüència del treball de grup i l'opinió sobre si l'experiència ha estat en general positiva o negativa.

Taula 1. Relació entre la freqüència d'experiències i la valoració del treball de grup

\begin{tabular}{|l|c|c|c|c|c|}
\cline { 2 - 6 } \multicolumn{1}{c|}{} & \multicolumn{2}{|c|}{ Experiències de treball de grup } & \multicolumn{2}{l|}{} \\
\hline $\begin{array}{l}\text { Valoració } \\
\text { treball de grup }\end{array}$ & $\begin{array}{c}\text { Majoria } \\
\text { assignatures }\end{array}$ & $\begin{array}{c}\text { Dos treballs } \\
\text { trimestre }\end{array}$ & $\begin{array}{c}\text { Algunes } \\
\text { ocasions }\end{array}$ & Total & $\begin{array}{c}\text { V } \\
\text { Cramer }\end{array}$ \\
\hline $\begin{array}{l}\text { Experiència } \\
\text { positiva }\end{array}$ & $62 \%$ & $50 \%$ & $40 \%$ & $53 \%$ & \\
\hline $\begin{array}{l}\text { Experiència } \\
\text { negativa }\end{array}$ & $38 \%$ & $50 \%$ & $60 \%$ & $47 \%$ & \\
\hline Total & $100(416)$ & $100(183)$ & $100(239)$ & $100(838)$ & $0,19^{* *}$ \\
\hline$\%$ horitzontals & $50 \%$ & $22 \%$ & $28 \%$ & $100(838)$ & \\
\hline
\end{tabular}

\section{Font: Elaboració pròpia}

Els resultats de la taula 1 mostren que la meitat aproximada dels estudiants considera que ha estat una experiència positiva i l'altra meitat negativa. D'altra banda, es pot observar que les experiències positives augmenten quan es posen en pràctica més exercicis de grup. Aquest resultat dóna suport a la idea que cal modificar la concepció pedagògica tradicional en l'ensenyament universitari.

A continuació, s'entra en la temàtica pròpia d'aquest apartat on es descriuen un conjunt d'indicadors que tenen a veure amb la percepció dels estudiants sobre les condicions de manteniment en relació amb el treball de grup. En primer Iloc, es tenen en compte les necessitats bàsiques i, en segon lloc, les condicions de seguretat.

\section{Necessitats bàsiques}

La taula 2 mostra la distribució de freqüències en dos indicadors i es constata que són majoria els estudiants que tenen importants impediments en aquests aspectes. El 63\% tenen moltes dificultats de reunir-se amb els companys i el 53\% moltes dificultats de realitzar-lo degut a la falta de temps, atesa la pressió de feina que tenen en els estudis. Aquests impediments representen els percentatges més elevats de totes les que experimenten els estudiants. D'acord amb el que ja s'ha indicat abans, quan les condicions de manteniment fallen, és poc probable que els factors motivadors puguin actuar adequadament.

És probable, doncs, que molts estudiants esquivin el treball de grup, o cerquin estratègies de sortida adaptant les seves preferències («Tanmateix per la feina que dóna no compensa»), per estalviar-se la frustració que genera una activitat que no es pot abastar adequadament.

(4) Cal dir que en fer les anàlisis tenint en compte les 10 titulacions estudiades en les 4 universitats s'han detectat diferències degut al diferent nivell d'aplicació d'aquesta metodologia però no s'esmenta en aquest article per qüestions d'espai. Per informació detallada es pot consultar Troiano et al. (2012). 
Taula 2. Dificultats percebudes per realitzar adequadament el treball de grup en les necessitats bàsiques

\begin{tabular}{|c|c|c|c|c|c|}
\hline $\begin{array}{c}\text { Dificultats necessitats } \\
\text { bàsiques }\end{array}$ & Poques & Regular & Moltes & Total & $\begin{array}{c}\text { Correlació VCr. amb } \\
\text { Valoració negativa TG }\end{array}$ \\
\hline Dificultat de reunir el grup & $17 \%$ & $20 \%$ & $63 \%$ & $100 \%(856)$ & $>\mathbf{0 , 0 5}$ NS \\
\hline Pressió excessiva de feina & $20 \%$ & $26 \%$ & $53 \%$ & $100 \%(856)$ & $>\mathbf{0 , 0 5}$ NS \\
\hline
\end{tabular}

\section{Font: Elaboració pròpia ${ }^{5}$}

La sisena columna de la taula 2 mostra la correlació entre aquestes dues variables i la valoració positiva o negativa del treball de grup, tal com s'ha explicat en la taula 1. Aquesta relació no és significativa, ja que segurament els estudiants han considerat que cap de les dues dificultats fan referència a l'experiència pròpiament dita del treball de grup, sinó a les condicions de l'entorn on l'han de posar en pràctica.

\section{Seguretat}

Sobre aquest tema hi ha dos conjunts d'informacions rellevants dels estudiants. En primer lloc, es mostren els resultats d'una bateria de preguntes del qüestionari que demanaven al responent que es fixés en el millor grup en què havia participat i sobre ell donés informació de les seves característiques. Es tracta d'un procediment indirecte per disposar d'informació sobre les preferències més compartides relacionades amb la seguretat.

Taula 3. Característiques del millor grup elegides pels estudiants

\begin{tabular}{|c|c|c|c|c|c|}
\hline & 2 & $3 \circ 4$ & $5 \circ 6$ & 7 i més & 856 \\
\hline $\begin{array}{l}\text { Nombre } \\
\text { d'estudiants }\end{array}$ & $10 \%$ & $56 \%$ & $20 \%$ & $14 \%$ & 100 \\
\hline $\begin{array}{l}\text { Criteri d'elecció } \\
\text { dels estudiants del } \\
\text { grup }\end{array}$ & $\begin{array}{l}\text { Estudiants } \\
\text { aplicats } \\
15 \%\end{array}$ & $\begin{array}{l}\text { Amics } \\
58 \%\end{array}$ & $\begin{array}{l}\text { Atzar } \\
\text { professorat } \\
14 \%\end{array}$ & $\begin{array}{l}\text { Atzar } \\
\text { estudiants } \\
13 \%\end{array}$ & $\begin{array}{l}830 \\
100\end{array}$ \\
\hline Tipus grup & $\begin{array}{l}\text { Estable } \\
58 \%\end{array}$ & $\begin{array}{l}\text { Per un sol } \\
\text { treball } \\
42 \%\end{array}$ & & & $\begin{array}{l}856 \\
100\end{array}$ \\
\hline Objectiu & $\begin{array}{l}\text { Problemes } \\
\text { aplicats } \\
18 \%\end{array}$ & $\begin{array}{l}\text { Temes } \\
\text { Teòrics } \\
17 \%\end{array}$ & $\begin{array}{l}\text { Projectes } \\
55 \%\end{array}$ & $\begin{array}{l}\text { Mixtes i } \\
\text { altres } \\
10 \%\end{array}$ & $\begin{array}{l}852 \\
100\end{array}$ \\
\hline
\end{tabular}

\section{Font: Elaboració pròpia}

Els resultats de la taula 3 mostren com la majoria d'estudiants prefereixen grups estables de 3 o 4 amics dedicats a la realització d'un projecte definit.

Una de les qüestions que afecta a la seguretat dels estudiants és la claredat dels criteris d'avaluació. Tot i que no tenim un indicador explícit sobre aquesta variable en relació al treball de grup, la taula 4 reflecteix el pes del sistema d'avaluació a l'hora de dedicar-se a una assignatura en concret.

(5) La darrera columna de la taula fa referència a la correlació entre la valoració negativa del treball en grup i les dificultats respecte a les necessitats bàsiques. 
Taula 4. Influència del sistema d'avaluació en la dedicació a una assignatura

\begin{tabular}{|l|c|c|c|c|}
\hline & Poca & Regular & Molta & Total \\
\hline $\begin{array}{l}\text { Sistema } \\
\text { avahuació }\end{array}$ & $19 \%$ & $30 \%$ & $\mathbf{5 0 \%}$ & $\begin{array}{c}100 \\
(860)\end{array}$ \\
\hline
\end{tabular}

Font: Elaboració pròpia

La meitat dels estudiants donen molta importància al sistema d'avaluació a l'hora de decidir l'actitud que tenen davant d'una determinada assignatura, la qual cosa és compartida per la majoria de recerques sobre aquests temes i d'aquí la importància de les propostes de la reforma de Bolonya que insisteix en aquest tema, almenys en les recomanacions de l'Agència per la Qualitat del Sistema Universitari de Catalunya-AQU).

A continuació, es fa referència als quatre indicadors dels que disposem per referirnos a les dificultats de seguretat.

Taula 5. Les dificultats en qüestions de seguretat en els treballs en grup

\begin{tabular}{|l|c|c|c|c|c|}
\hline Tipus de dificultat & Poques & Regular & Moltes & Total & $\begin{array}{c}\text { Correlació VCr. } \\
\text { amb valoració } \\
\text { negativa TG }\end{array}$ \\
\hline $\begin{array}{l}\text { Manca d'orientació del } \\
\text { professorat }\end{array}$ & $37 \%$ & $33 \%$ & $30 \%$ & $\begin{array}{l}100 \% \\
(856)\end{array}$ & $0,08^{*}$ \\
\hline Grups massa grans & $51 \%$ & $22 \%$ & $27 \%$ & $\begin{array}{l}100 \% \\
(856)\end{array}$ & $0.13^{* *}$ \\
\hline Manca d'adequació & $40 \%$ & $36 \%$ & $24 \%$ & $\begin{array}{l}100 \% \\
(856)\end{array}$ & $0,11^{* *}$ \\
\hline $\begin{array}{l}\text { Falta d'experiència dels } \\
\text { estudiants }\end{array}$ & $47 \%$ & $30 \%$ & $23 \%$ & $\begin{array}{l}100 \% \\
(856)\end{array}$ & $0,12^{* *}$ \\
\hline
\end{tabular}

Font: Elaboració pròpia

La darrera columna de la taula fa referència a la correlació entre la valoració negativa del treball en grup i les dificultats respecte a les necessitats bàsiques. En aquest cas sí que hi ha correlació ja que, per exemple, el $27 \%$ que diuen tenir moltes dificultats tenen una valoració més negativa del treball en grup que el $51 \%$ que diuen tenir-ne poques.

En conjunt podem observar que dintre de les condicions de manteniment tenen més importància les que fan referència a les necessitats bàsiques que les que tenen a veure amb la seguretat, ja que els que opinen que en tenen «poques» es mouen entre el $50 \%$ (grandària dels grups) i el 37\% (manca d'orientació del professorat). Això, no obstant, val la pena remarcar que a prop d'una tercera part dels estudiants consideren que no han rebut l'orientació adequada del professorat, i que els grups són massa grans, i una quarta part aproximada considera que la feina és poc adequada per realitzar-la en grup, i als estudiants els hi falta experiència.

\section{Resultats sobre els motivadors: inclusió social, reconeixement i autorealització}

Un cop analitzades les condicions de manteniment (higièniques), que són una condició necessària però no suficient en relació a les necessitats humanes, pugem un graó més en la piràmide de Maslow per fixar-nos en les necessitats socials tan característiques de l'espècie humana. Segons el marc teòric exposat, la solució adequada d'aquestes necessitats funciona com un motivador de l'activitat humana, en aquest cas concret orientada a l'estudi i l'aprenentatge.

Igual que en l'apartat anterior distingim entre la manera de funcionar del millor grup en el que els estudiants han participat, taula 6, per fixar-nos en la taula 7 en les 
principals dificultats que han sorgit d'aquests tipus en la posada en pràctica del treball de grup.

\section{Inclusió social}

La manera més freqüent d'organitzar el treball de grup que posen en pràctica quasi la majoria dels estudiants és la combinació del treball individual, per realitzar cadascú una part del treball, amb la discussió conjunta de la feina feta pel grup que sovint conclou amb unes conclusions conjuntes. De fet, en les entrevistes prèvies als estudiants es va manifestar una manera d'organitzar-se anomenada «disjuntiva» en la qual cada membre del grup realitza aquella tasca en la que és més competent.

Taula 6. L'organització del treball de grup en el millor grup

\begin{tabular}{|l|c|c|c|c|c|}
\hline \multicolumn{5}{|c|}{ Freqü̈ències dels tipus d'organització del millor grup } \\
\hline Elaboració & Conjunts & $\begin{array}{c}\text { Individual } \\
\text { dis cuss ió } \\
\text { resultats }\end{array}$ & $\begin{array}{c}\text { Individual } \\
\text { conchusions } \\
\text { conjuntes }\end{array}$ & $\begin{array}{c}\text { Agregat } \\
\text { individual i } \\
\text { Mixtes }\end{array}$ & 837 \\
& $21 \%$ & $47 \%$ & $17 \%$ & $15 \%$ & $100 \%$ \\
\hline Coordinació & Un lider & Tots & Altres & & 840 \\
& $20 \%$ & $79 \%$ & $1 \%$ & & $100 \%$ \\
\hline
\end{tabular}

Front: Elaboració pròpia

En alguns casos (15\%) es produeix una suma simple de les aportacions de cadascú. Un problema similar apareix quan els membres del grup només discuteixen les conclusions, ja que, a vegades ni tan sols llegeixen les parts que han fet els companys (17\%) (taula 6).

En definitiva, la cooperació en grup és un mecanisme instintiu que funciona, però segons quines són les condicions del context o dels individus que s'apleguen pot ser més o menys eficaç de cara l'aprenentatge i no és una qüestió fàcil controlar adequadament aquestes situacions per part del professorat.

Tal com es pot veure en la segona fila de la taula 7 només un $20 \%$ dels estudiants participen en grups on hi ha un líder reconegut, la gran majoria funciona a partir del lideratge compartit. Resultats experimentals recents mostren que tant els líders emergents -com seria el cas del $20 \%$ dels estudiants-com el lideratge compartit -que seria el cas del 79\% restant- poden tenir resultats igualment positius en la realització de les tasques. Sembla que depèn de les circumstàncies contextuals (Nijstad, 2009, p. 191).

Probablement els grups universitaris són relativament petits i la necessitat de la coordinació per part d'un líder no sigui tan necessària com en els grups grans. Blau (1964) assenyala que les necessitats de coordinació generen competència per l'estatus i possibilitats de control per part del líder dels altres membres del grup, la qual cosa pot generar una pèrdua de legitimació del líder atès que els altres membres no accepten fàcilment el control. Aquests mecanismes sembla que funcionen entre els universitaris ja que, en les entrevistes, es va poder constatar un cert rebuig al lideratge sobretot quan un individu pretenia imposar la seva voluntat als demés.

De la mateixa manera que en els apartats anteriors s'ha parlat de les dificultats de les condicions de manteniment de cara a la realització d'un treball de grup eficient, a continuació es tracten les dificultats que sorgeixen del funcionament intrínsec del grup. 
Taula 7. Dificultats referents a la inclusió social en la realització dels treballs de grup

\begin{tabular}{|l|c|c|c|c|c|}
\hline $\begin{array}{l}\text { Dificultats } \\
\text { d'inclusió social }\end{array}$ & Poques & Regular & Moltes & Total & $\begin{array}{c}\text { Correlació (VCr.) amb } \\
\text { valoració negativa TG }\end{array}$ \\
\hline Aprofitats & $31 \%$ & $21 \%$ & $48 \%$ & $\begin{array}{l}100 \% \\
(856)\end{array}$ & $0,12^{* *}$ \\
\hline $\begin{array}{l}\text { Conflictes } \\
\text { companys }\end{array}$ & $56 \%$ & $25 \%$ & $19 \%$ & $\begin{array}{l}100 \% \\
(856)\end{array}$ & $0,14^{*}$ \\
\hline Massa amistat & $55 \%$ & $27 \%$ & $18 \%$ & $\begin{array}{l}100 \% \\
(856)\end{array}$ & $>0,05 \mathrm{NS}$ \\
\hline Manca de confiança & $47 \%$ & $28 \%$ & $25 \%$ & $\begin{array}{l}100 \% \\
(856)\end{array}$ & $0,17^{* *}$ \\
\hline Falta de lideratge & $53 \%$ & $29 \%$ & $18 \%$ & $\begin{array}{l}100 \% \\
(856)\end{array}$ & $0,07^{*}$ \\
\hline
\end{tabular}

Font: Elaboració pròpia

Pràcticament al mateix nivell que les dificultats generades per la manca de condicions de manteniment -bàsiques i de seguretat- se situen les dificultats generades per la presència d'estudiants «aprofitats» la qual cosa és assenyalada per quasi la meitat dels estudiants. En el mateix text de Nijstad (2009) considera que els aprofitats apareixen quan alguns membres del grup perceben que els seus esforços no són necessaris. Sense negar aquesta possibilitat «bondadosa» com un element que facilita aquesta conducta, sembla que els aprofitats són comuns en tots els grups humans com un mecanisme biològic de caràcter adaptatiu que justament planteja problemes a la cooperació, si no es controla degudament.

En els altres aspectes que es mostren en la taula s'observa un percentatge d'estudiants afectats més reduït. Falta de confiança, falta de lideratge, massa amistat, conflictes entre companys. Tots ells incrementen la valoració negativa davant de la pràctica del treball de grup, llevat de l'amistat que no presenta una diferència significativa, tal com es pot veure en la darrera columna de la taula 7.

Es pot observar com la falta de lideratge també a vegades és una dificultat encara que la gran majoria dels estudiants es decanten per considerar que el millor grup en el que han participat és un grup sense líder. D'alguna manera, és una constatació que segurament pot generar problemes de coordinació.

Els altres ítems tots estan relacionats amb la temàtica dels aprofitats. Tal com s'ha vist anteriorment els estudiants prefereixen els amics per formar un grup, però tal com s'ha pogut constatar en les entrevistes a vegades els amics no s'esforcen adequadament justament perquè l'amistat els ho permet atès que és més difícil castigar a un amic. La falta de confiança i els conflictes entre els membres sovint connecten amb el mateix problema.

La taula 8 mostra les diferents respostes que donen els estudiants davant dels companys de grup que s'aprofiten de la seva feina i no contribueixen als costos col-lectius. 
Taula 8. Accions que prenen els estudiants davant del comportament dels aprofitats

\begin{tabular}{|l|c|}
\hline Parlar amb el professor/a & $22 \%$ \\
\hline Excloure'1 del grup & $10 \%$ \\
\hline No acceptar-lo una altra vegada & $60 \%$ \\
\hline No fer res & $8 \%$ \\
\hline Total & $100 \%(833)$ \\
\hline
\end{tabular}

Font: Elaboració pròpia

Les dades mostren que la gran majoria d'estudiants perceben la conducta dels aprofitats com injusta i, per tant, responen majoritàriament amb mecanismes o bé de càstig directe (parlar amb el professor -22\%- o excloure'l del grup -10\%-) o bé d'evitació d'aquesta situació de cara al futur (60\%). En principi, la primera conducta respon més aviat al mecanisme de la reciprocitat forta, és a dir, a un requisit emocional de caire moral que fa justícia, mentre que la segona sembla més vinculada al mecanisme de la reciprocitat feble, sensible al càlcul de costos i beneficis. Val a dir que, en la recerca qualitativa, varem poder constatar que alguns estudiants entrevistats tenien la sensació de «fer el ridícul» i se sentien indignats per aquesta situació (Masjuan i Elias, 2012).

Un conjunt relativament reduït d'estudiants contesta que «no fa res» (8\%), en el sentit que prefereix absorbir el problema fent la feina que correspon a l'altra persona i deixar-ho córrer. A partir de l'anàlisi qualitativa es va veure que aquests perfils es donen més quan hi ha relacions d'amistat, o situacions concretes de limitacions en els companys com ara manca de temps d'un company perquè necessita treballar o limitacions en algunes habilitats. En definitiva, circumstàncies que incentiven la solidaritat entre els companys del mateix grup. Es pot afegir que la impressió a partir del treball qualitatiu va ser que aquest tipus de conductes podrien ser més freqüents del que reflecteixen les dades estadístiques.

\section{Ego status (Reconeixement)}

Un cop descrites les característiques organitzatives dels grups de treball i les dificultats que es poden generar en els processos interns d'interacció, es realitza una anàlisi de com funcionen els factors motivadors en aquells aspectes que tenen a veure amb el reconeixement institucional de l'esforç dels estudiants. En definitiva, ens estem referint a la percepció del comportament del professorat en les tasques d'avaluació.

Com s'ha vist en el model d'anàlisi, Prescott i Simpson (2004) associen l'assoliment del reconeixement institucional a les qualificacions acadèmiques $i$ al retorn del professorat sobre el treball dels estudiants.

En l'apartat sobre la seguretat ja s'ha indicat la importància que els estudiants donen a les avaluacions, però també estan connectades amb el tema d'aquest apartat sobre el reconeixement per part del professorat i dels altres companys de la feina feta. 
Taula 9. Procediments d'avaluació en els grups millors

\begin{tabular}{|c|c|c|c|c|}
\hline $\begin{array}{c}\text { Procediment } \\
\text { d'avaluació }\end{array}$ & $\begin{array}{c}\text { Professor nota } \\
\text { única } \\
87 \%\end{array}$ & $\begin{array}{c}\text { Professor notes } \\
\text { diferents } \\
9 \%\end{array}$ & $\begin{array}{c}\text { Professor i } \\
\text { estudiants } \\
4 \%\end{array}$ & 841 \\
\hline Justícia de la & $\mathrm{Si}$ & $\mathrm{No}$ & & 100 \\
nota & $\mathbf{8 0 \%}$ & $19 \%$ & & 100 \\
\hline
\end{tabular}

\section{Font: Elaboració pròpia}

La taula 9 només informa que en la gran majoria d'experiències de grup l'avaluació es considera justa però és el professor/a qui posa la nota. Les entrevistes qualitatives mostraven la dificultat de fer justícia amb aquest procediment atès que sovint els estudiants aprofitats es beneficiaven de l'esforç dels altres sense pagar els costos.

\section{Taula 10. Dificultats sorgides del poc reconeixement per part del professorat a les feines realitzades en grup}

Freqüiència de les dificultats

\begin{tabular}{|l|c|c|c|c|c|}
\hline $\begin{array}{c}\text { Tipus de manca de } \\
\text { reconeixement }\end{array}$ & Poques & Regular & Moltes & Total & $\begin{array}{c}\text { Correlació (VCr) amb } \\
\text { Valoració negativa T.Grup }\end{array}$ \\
\hline $\begin{array}{l}\text { Poc pes de la nota del } \\
\text { treball de grup en la } \\
\text { nota final }\end{array}$ & $29 \%$ & $25 \%$ & $\mathbf{4 6 \%}$ & $\begin{array}{c}100 \% \\
(856)\end{array}$ & $\mathrm{S}>0,05 \mathrm{NS}$ \\
\hline Avaluació injusta & $\mathbf{4 4} \%$ & $31 \%$ & $25 \%$ & $\begin{array}{c}100 \% \\
(856)\end{array}$ & $\mathrm{S}>0,05 \mathrm{NS}$ \\
\hline
\end{tabular}

Font: Elaboració pròpia

Els estudiants es queixen que la feina que els ha comportat el treball de grup no ha estat degudament recompensada ja que en la nota final han comptat més els exàmens individuals. Al seu torn, una mica més de la meitat dels estudiants considera més o menys injusta l'avaluació rebuda $-31 \%+25 \%-$.

Les dues dificultats que expressen els estudiants pel que fa al reconeixement del professorat no mostren cap associació significativa amb la valoració del funcionament dels grups, segurament perquè les avaluacions no depenen del grup d'estudiants sinó només del professorat. De fet una avaluació injusta afecta a una de les condicions de l'èxit d'un grup de treball. Vroom (1964) afirma que els estudiants redueixen l'esforç quan perceben que no serà degudament avaluat, i afirma també que quan «les contribucions individuals a la realització del grup no són identificades ni avaluades provoquen tot sovint ganduleria».

\section{Realització personal}

Prescott i Simpson (2004) associen l'autorealització a les experiències d'aprenentatge autònom i creatiu. D'una manera aproximativa aquest apartat vol respondre fins a quin punt s'assoleixen aquests objectius. Així, s'analitzen dos tipus d'indicadors de les realitzacions dels estudiants, una més objectiva a partir de les notes de l'expedient acadèmic, i l'altre més subjectiva consistent en la percepció que ells mateixos tenen del progrés realitzat en diferents aspectes Iligats a l'aprenentatge universitari. L'objectiu serà veure fins a quin punt influeix la freqüència del treball en grup en els resultats acadèmics i en 
la percepció subjectiva del progrés en els coneixements, controlant les diferències en les capacitats ${ }^{6}$ del nivell d'entrada a la universitat.

Taula 11. Relació entre la freqüència del treball de grup i l'expedient acadèmic condicionat pel tipus d'accés d'entrada a la universitat

Freqüència de treball de grup

\begin{tabular}{|l|c|c|c|c|c|c|}
\hline $\begin{array}{l}\text { Accés a la } \\
\text { universitat }\end{array}$ & $\begin{array}{l}\text { Expedient } \\
\text { acadèmic } \\
\text { universitat }\end{array}$ & $\begin{array}{l}\text { La mojoria } \\
\boldsymbol{d}^{\prime} \text { assign. }\end{array}$ & $\begin{array}{l}\text { Dos treb alls } \\
\text { semestre }\end{array}$ & $\begin{array}{l}\text { Algunes } \\
\text { ocasions }\end{array}$ & Total & VCramer \\
\hline Cicles & Not. + Excel. & $56 \%$ & $39 \%$ & $31 \%$ & $46 \%$ & \\
form atius & Aprovats & $44 \%$ & $61 \%$ & $69 \%$ & $54 \%$ & $0,22^{*}$ \\
& Total & $100(147)$ & $100(51)$ & $100(71)$ & $100(269)$ & \\
\hline BUP Nota & Not+Excel. & $46 \%$ & $33 \%$ & $21 \%$ & $35 \%$ & \\
accés baixa & Aprovats & $54 \%$ & $67 \%$ & $79 \%$ & $65 \%$ & $0,23^{*}$ \\
& Total & $100(119)$ & $100(66)$ & $100(85)$ & $100(270)$ & \\
\hline BUP Nota & Not+Excel. & $72 \% *$ & $62 \%$ & $44 \%$ & $62 \%$ & \\
accés alta & Aprovats & $28 \%$ & $38 \%$ & $56 \%$ & $38 \%$ & $0,24 *$ \\
& Total & $100(141)$ & $100(61)$ & $100(82)$ & $100(284)$ & \\
\hline
\end{tabular}

Font: Elaboració pròpia

Abans d'abordar l'objectiu a partir de les anàlisis presentades anteriorment, es constata la necessitat de separar les notes d'accés segons els col-lectius d'entrada a la universitat ja que les capacitats dels estudiants afecten els resultats acadèmics. Per aquesta raó, a l'hora de contrastar aquestes hipòtesis s'han separat tres col-lectius d'estudiants, segons la nota d'entrada a la universitat en el cas dels batxillers, i el col.lectiu que entra a la universitat procedent dels cicles formatius de formació professional. Les anàlisis es controlen, doncs, per les capacitats dels estudiants.

Es pot observar a la taula 11 com els estudiants provinents de batxillerat que accedeixen a la universitat amb la nota més alta tenen millor expedient que els que provenen dels cicles formatius de formació professional i aquests tenen millors notes que els batxillers que tenen notes baixes d'accés a la universitat. En les tres situacions, però, la relació entre la freqüència de treball de grup i les qualificacions és positiva i significativa estadísticament. Per exemple, en el cas dels cicles professionals les qualificacions de notables i excel.lents, segons la freqüència del treball de grup, passen de $56 \%>39 \%>31 \%$ amb una correlació de 0,22 significativa. Una cosa semblant passa en els altres itineraris.

La taula 12 mostra els resultats sobre la percepció subjectiva dels estudiants pel que fa al progrés en els coneixements assolits i es mostra com la freqüència del treball de grup no influeix en la percepció subjectiva del progrés en els coneixements dels estudiants que provenen dels cicles formatius o els batxillers amb nota alta. En canvi influeix en els batxillers amb nota baixa d'accés.

(6) Al no disposar en el qüestionari d'un indicador de capacitats s'utilitza com a proxi les notes d'entrada a la universitat, nota que es diferencial segons el collectiu d'entrada a la universitat. 
Taula 12. Relació entre la freqüència del treball de grup i la percepció del progrés en els coneixements condicionat pel procediment d'accés a la universitat

\begin{tabular}{|c|c|c|c|c|c|c|}
\hline & \multicolumn{4}{|c|}{ Freqüència de treball de grup } & \multirow[b]{2}{*}{ Total } & \multirow[b]{2}{*}{$\begin{array}{c}\text { V. } \\
\text { Cramer }\end{array}$} \\
\hline $\begin{array}{l}\text { Accés a la } \\
\text { universitat }\end{array}$ & $\begin{array}{c}\text { Progrés en } \\
\text { coneixements }\end{array}$ & $\begin{array}{c}\text { La majoria } \\
\text { d'assignatures }\end{array}$ & $\begin{array}{c}\text { Dos treballs al } \\
\text { semestre }\end{array}$ & $\begin{array}{l}\text { Algunes } \\
\text { oca sions }\end{array}$ & & \\
\hline \multirow{3}{*}{$\begin{array}{c}\text { Cicles } \\
\text { formatius }\end{array}$} & Molt & $65 \%$ & $65 \%$ & 61 & $64 \%$ & $S>0.05$ \\
\hline & Poc & $35 \%$ & $35 \%$ & 39 & $36 \%$ & NS \\
\hline & Total & $100 \%(150)$ & $100 \%(52)$ & $100 \%(74)$ & $\begin{array}{l}100 \% \\
(276) \\
\end{array}$ & \\
\hline \multirow{3}{*}{$\begin{array}{c}\text { Batx. nota } \\
\text { accés badxa }\end{array}$} & Molt & $79 \%$ & $72 \%$ & $68 \%$ & $73 \%$ & \multirow{3}{*}{0,19 * } \\
\hline & Poc & $21 \%$ & $28 \%$ & $32 \%$ & $27 \%$ & \\
\hline & Total & $100(123)$ & $100(67)$ & $100(88)$ & $\begin{array}{l}100 \% \\
(278) \\
\end{array}$ & \\
\hline \multirow{3}{*}{$\begin{array}{l}\text { Batx. nota } \\
\text { accés alta }\end{array}$} & Molt & $75 \%$ & $71 \%$ & $73 \%$ & $73 \%$ & $S>0,05$ \\
\hline & Poc & $25 \%$ & $29 \%$ & $27 \%$ & $27 \%$ & NS \\
\hline & Total & $100 \%(145)$ & $100 \%(63)$ & $100(84)$ & $\begin{array}{l}100 \% \\
(292)\end{array}$ & \\
\hline
\end{tabular}

Progrés en coneixements: Molt= Molt+Bastant; Poc=Indiferent+poc+gens

\section{Font: Elaboració pròpia}

En aquest cas, tampoc hi ha relació significativa clara entre la freqüència de treball de grup i la percepció del progrés en els coneixements, tot i que, en el cas dels batxillers amb nota baixa d'accés, la VCramer és significativa però els residus corregits no arriben a 2.

Una altra conclusió important d'aquesta anàlisi no prevista és que no hi ha concordança entre les notes assolides i la percepció del progrés en els coneixements. La freqüència del treball de grup influencia en els resultats acadèmics però no en la percepció del progrés en els coneixements de la majoria d'estudiants, llevat dels estudiants de batxillerat amb notes baixes.

Un cop analitzada la relació directa entre el treball de grup, les qualificacions i la percepció del progrés acadèmic i personal, controlades per un proxi de les capacitats dels estudiants, cal analitzar com es comporten les variables intermèdies, és a dir, la identificació amb la universitat i l'augment de les interaccions entre els companys de grup.

La taula 13 dóna les dades de la relació entre la freqüència del treball de grup i la identificació amb la universitat ${ }^{7}$.

Taula 13. Relació entre la freqüència del treball de grup i l'escala d'identificació a partir de les mitjanes

Freqüèncta del treball de grup

\begin{tabular}{|c|c|c|c|c|c|c|}
\hline $\begin{array}{c}\text { Es cala } \\
\text { d'identificació }\end{array}$ & $\begin{array}{c}\text { TG en la } \\
\text { majoria } \\
\text { d'assignatures }\end{array}$ & $\begin{array}{c}\text { Dos treballs } \\
\text { de grup per } \\
\text { semestre }\end{array}$ & $\begin{array}{c}\text { Només en } \\
\text { algunes } \\
\text { ocasions }\end{array}$ & Total & F. & SIG \\
\hline Mitjanes & 15,6 & 15,4 & 15,4 & 15,5 & 1 & $>0,05 \mathrm{NS}$ \\
\hline D. típica & 2,7 & 2,6 & 2,8 & 2,7 & & \\
\hline
\end{tabular}

Font: Elaboració pròpia

(7) La variable identificació respon a una escala de quatre indicadors, per això utilitzem la mitjana de puntuacions que poden anar de 5 a 20. 
Sembla que la freqüència del treball de grup no influeix en el nivell d'identificació amb la universitat (taula 13). Aquest resultat indica que aquesta relació no és directa i, per tant, en tot cas, podria dependre de la manera com és faci el treball de grup i de les conseqüències que tingui per la conducta dels estudiants.

Les taules 14 i 15 mostren la relació directa entre la freqüència del treball de grup i la interacció comunicativa entre els estudiants i entre aquests i el professorat i es conclou que la freqüència del treball de grup influeix positivament en les relacions que els estudiants estableixen entre ells i amb el professorat. La relació és més intensa en els estudiants entre ells $\left(0,27^{*}\right)$ que entre ells i el professorat $\left(0,17^{*}\right)$.

Taula 14. Relació entre la freqüència del treball de grup i les interaccions entre els estudiants

\begin{tabular}{|c|c|c|c|c|c|}
\hline & \multicolumn{4}{|c|}{ Freqüència de treball de grup } & \multirow[b]{2}{*}{ VCramer } \\
\hline $\begin{array}{c}\text { Freqüència de } \\
\text { relacions entre } \\
\text { estudiants }\end{array}$ & $\begin{array}{c}\text { TG en la } \\
\text { majoria } \\
\text { d'assignatures }\end{array}$ & $\begin{array}{c}\text { Dos treballs } \\
\text { de grup per } \\
\text { semestre }\end{array}$ & $\begin{array}{c}\text { Només en } \\
\text { algunes } \\
\text { ocasions }\end{array}$ & Total & \\
\hline $\begin{array}{c}\text { Habitualment }+ \\
\text { sovint }\end{array}$ & $58 \% *$ & $43 \%$ & $28 \%$ & $46 \%$ & \multirow[b]{2}{*}{$0,27^{*}$} \\
\hline $\begin{array}{c}\text { Esporàdicament } \\
+ \text { quasi mai }+ \\
\text { mai }\end{array}$ & $43 \%$ & $57 \%$ & $72 \%$ & $54 \%$ & \\
\hline Total & $100 \%(421)$ & $100 \%(183)$ & $100 \%(246)$ & $100 \%(850)$ & \\
\hline
\end{tabular}

Font: Elaboració pròpia

Taula 15. Relació entre la freqüència del treball de grup i les interaccions dels estudiants amb el professorat

\begin{tabular}{|c|c|c|c|c|c|}
\hline & \multicolumn{4}{|c|}{ Freqüència de treball de grup } & \\
\hline $\begin{array}{c}\text { Freqüència de } \\
\text { relacions entre } \\
\text { estudiants i } \\
\text { professorat }\end{array}$ & $\begin{array}{c}\text { TG en la } \\
\text { majoria } \\
\text { d'assignatures }\end{array}$ & $\begin{array}{c}\text { Dos treballs } \\
\text { de grup per } \\
\text { semestre }\end{array}$ & $\begin{array}{c}\text { Només en } \\
\text { algunes } \\
\text { ocasions }\end{array}$ & Total & VCramer \\
\hline $\begin{array}{c}\text { Habitualment }+ \\
\text { sovint }\end{array}$ & $37 \% *$ & $29 \%$ & $22 \%$ & $31 \%$ & \\
\hline $\begin{array}{c}\text { Esporàdicament } \\
+ \text { quasi mai }+ \\
\text { mai }\end{array}$ & $63 \%$ & $71 \%$ & $78 \%$ & $69 \%$ & $0,17^{*}$ \\
\hline Total & $100 \%(421)$ & $100 \%(183)$ & $100 \%(246)$ & $100 \%(850)$ & \\
\hline
\end{tabular}

\section{Font: Elaboració pròpia}

Mentre que en el conjunt de la mostra un $46 \%$ dels estudiants tenen molta relació entre ells, entre els que practiquen el treball de grup aquest s'eleva al 58\%. Entre els estudiants i el professorat hi ha un percentatge inferior de relacions freqüents (31\% comparat amb 46\%), i la relació -tot i donar-se en la mateixa direcció que abans- és més feble.

Aquesta relació té un significat teòric rellevant, atès que mostra com a nivell micro el treball de grup és un procediment que facilita el contacte entre els estudiants i entre estudiants i el professorat.

A continuació, cal posar en relació el que passa en el nivell micro a través de l'augment de relacions entre els estudiants i, entre ells i el professorat, i el que passa en 
el nivell d'integració amb la universitat dels estudiants a partir de la variable que mesura el nivell d'identificació amb la institució.

Taula 16. Relació entre la interacció dels estudiants i el nivell d'identificació a la universitat

\begin{tabular}{|c|c|c|c|c|c|c|}
\hline $\begin{array}{c}\text { Fre qüència } \\
\text { contactes } \\
\text { companys }\end{array}$ & Mai & $\begin{array}{c}\text { Quasi } \\
\text { mai }\end{array}$ & $\begin{array}{c}\text { Esporàdic } \\
\text { ament }\end{array}$ & Sovint & $\begin{array}{c}\text { Habüual } \\
\text { ment }\end{array}$ & Total \\
\hline $\begin{array}{c}\text { Mitjana nive ll } \\
\text { d'ide ntific ació }\end{array}$ & $11,1(8)$ & $12,5(40)$ & $14,2(119)$ & $15(283)$ & $16,6(404)$ & $15,5(854)$ \\
\hline Des viació T. & 3,9 & 3,1 & 2,7 & 2,4 & 2,2 & 2,7 \\
\hline
\end{tabular}

Sig. 0,000 Eta 0,45 Eta quadrat 0,20

\section{Font: Elaboració pròpia}

Taula 17. Relació entre la interacció dels estudiants amb el professorat i el nivell d'identificació amb la universitat

\begin{tabular}{|c|c|c|c|c|c|c|}
\hline $\begin{array}{c}\text { Freqüència } \\
\text { contacte amb } \\
\text { professorat }\end{array}$ & Mai & $\begin{array}{c}\text { Quasi } \\
\text { mai }\end{array}$ & $\begin{array}{c}\text { Esporàdic } \\
\text { ament }\end{array}$ & Sovint & $\begin{array}{c}\text { Habìual } \\
\text { ment }\end{array}$ & Total \\
\hline $\begin{array}{c}\text { Mitjana nivell } \\
\text { d'identificació }\end{array}$ & $14,2(90)$ & $15,2(255)$ & $15,6(321)$ & $16(160)$ & $16(27)$ & 853 \\
\hline Desviació T & 3,2 & 2,7 & 2,4 & 2,6 & 2,7 & 2,7 \\
\hline
\end{tabular}

Sig 0,000 Eta 0,20 Eta quadrat 0,04

Font: Elaboració pròpia

Les taules 16 i 17 mostren com l'augment de les relacions entre els estudiants i entre els estudiants i el professorat augmenten el nivell d'identificació dels estudiants amb la universitat. D'aquesta manera la institucionalització del treball de grup, a través d'incrementar la relació entre els companys, contribueix al fet que els estudiants se sentin més identificats amb la institució universitària.

Finalment, cal analitzar la relació entre la identificació a la universitat i les dues variables dependents fonamentals: La relació entre el nivell d'identificació i l'expedient acadèmic i la percepció del propi progrés.

Taula 18. Relació entre la identificació amb la universitat i les notes assolides, controlat per I'itinerari d'accés a la universitat i la nota d'accés en el cas dels batxillers

Nivell d'identificació $\quad$ Controlat per itineraris d'entrada

\begin{tabular}{|l|c|c|c|c|c|c|c|}
\hline $\begin{array}{l}\text { Nota } \\
\text { expedient }\end{array}$ & $\begin{array}{c}\text { Ident. } \\
\text { baixa }\end{array}$ & $\begin{array}{c}\text { Ident. } \\
\text { alta }\end{array}$ & Total & $\begin{array}{l}\text { Cicles } \\
\text { formatius }\end{array}$ & $\begin{array}{l}\text { Batxillerat } \\
\text { Nota baixa }\end{array}$ & $\begin{array}{l}\text { Batxillerat } \\
\text { Nota alta }\end{array}$ & Total \\
\hline $\begin{array}{l}\text { Notable o } \\
\text { excel-lent }\end{array}$ & $46 \%$ & $49 \%$ & $48 \%$ & & & & \\
\hline Aprovat & $54 \%$ & $51 \%$ & $52 \%$ & & & & \\
\hline Total & $\begin{array}{l}100 \% \\
(384)\end{array}$ & $\begin{array}{l}100 \% \\
(452)\end{array}$ & $\begin{array}{l}100 \% \\
(836)\end{array}$ & $\begin{array}{l}\text { VC } 0,06 \\
\text { S>0,05 } \\
\text { NS }\end{array}$ & $\begin{array}{l}\text { VC } 0,08 \\
\text { S>0 } 0,05 \\
\text { NS }\end{array}$ & $\begin{array}{l}\text { VC } 0,00 \\
\text { S>0 } 0,05 \\
\text { NS }\end{array}$ & $\begin{array}{l}\text { VC } 0,04 \\
\text { S>0 } 0,05 \\
\text { NS }\end{array}$ \\
\hline
\end{tabular}

Font: Elaboració pròpia

El nivell d'identificació amb la universitat, condicionat pels itineraris i les notes d'entrada, no mostra cap influència significativa amb l'expedient acadèmic. Observis 
(taula 18) que les relacions mesurades pel coeficient V Cramer són baixes, i en cap cas significatives.

La taula 19 es refereix a la relació entre el nivell d'identificació amb la universitat i la percepció subjectiva del progrés acadèmic i personal durant la seva estada a la universitat. Es contemplen sis indicadors que abracen coneixements, habilitats i actituds.

Taula 19. Relació entre la identificació a la universitat i la percepció del progrés acadèmic $i$ personal, controlat per l'itinerari la nota d'accés en el cas dels batxillers

\begin{tabular}{|c|c|c|c|c|c|c|c|}
\hline $\begin{array}{l}\text { Molt }+ \text { Bastant } \\
\text { en la percepció } \\
\text { de progrés en: }\end{array}$ & $\begin{array}{c}\text { Identificació } \\
\text { baixa }\end{array}$ & $\begin{array}{c}\text { Identificació } \\
\text { alta }\end{array}$ & Total & $\begin{array}{c}\text { VCram. } \\
\text { Total }\end{array}$ & $\begin{array}{l}\text { VCrom. } \\
\text { Cicles } \\
\text { Form. }\end{array}$ & $\begin{array}{l}\text { VCramer } \\
\text { Nota } \\
\text { accés } \\
\text { baixa }\end{array}$ & $\begin{array}{l}\text { VCromer } \\
\text { Nota } \\
\text { accés alta }\end{array}$ \\
\hline Coneixements & $63 \%$ & $78 \%$ * & $71 \%$ & $0,16^{*}$ & 0,14 & $0,21 *$ & $0,17^{*}$ \\
\hline Metodologia & $51 \%$ & $65 \%$ * & $58 \%$ & $0,15^{\star}$ & $0.20^{*}$ & 0,13 & $0,15^{*}$ \\
\hline C. professionals & $56 \%$ & $67 \%$ * & $61 \%$ & $0,11^{*}$ & $0,17^{*}$ & 0,05 & $0,16^{*}$ \\
\hline C. personal & $62 \%$ & $78 \% *$ & $69 \%$ & $0,18^{*}$ & $0,19^{*}$ & $0,22^{*}$ & $0,21^{*}$ \\
\hline C. transwersals & $38 \%$ & $48 \%$ & $43 \%$ & $0,13^{*}$ & 0,13 & $0,18^{*}$ & 0,13 \\
\hline Aprofitar temps & $50 \%$ & $65 \% *$ & $57 \%$ & $0,15^{*}$ & 0,12 & $0,15^{*}$ & $0,21^{*}$ \\
\hline Esforc & $55 \%$ & $65 \% *$ & $60 \%$ & $0,11^{*}$ & 0,09 & $0,15^{*}$ & 0,11 \\
\hline Total aprox & $\begin{array}{l}100 \% \\
(440)\end{array}$ & $\begin{array}{l}100 \% \\
(404)\end{array}$ & $\begin{array}{l}100 \% \\
(844)\end{array}$ & & & & \\
\hline
\end{tabular}

Observacions: La darrera fila indica la base del càlcul del percentatge de les diferents files. S'indica aproximat perquè el nombre de respostes a cada indicador no és ex actament el mateix, però amb poquissimes diferències.

Els percentatges de cada fila correspon als estudiants que indiquen un progrés alt en les diferents variables que correspon a la suma dels dos valors del qüestionari 'molt' $i$ 'bastant' entre cinc possibilitats, el complement a 100 correspon a 'indiferent', 'poc' $i$ 'gens'.

\section{Font: Elaboració pròpia}

La taula 19 mostra com el nivell d'identificació, condicionat pels tres itineraris d'entrada, mostra un efecte positiu, relativament important, en la percepció subjectiva del progrés en el coneixement i en les altres habilitats dels estudiants mesurades. És a dir, que la freqüència del treball de grup només influeix en la percepció del progrés acadèmic i personal dels estudiants quan a través de l'increment de les interaccions millora la identificació dels estudiants amb la universitat.

És interessant fixar-se, en primer lloc, en l'ordenació dels diferents aspectes estudiats per veure en quins consideren que progressen més i en quins menys. En primer lloc, els coneixements (71\%), seguit pel progrés personal (69\%), la professionalització (61\%), l'esforç (60\%), la metodologia d'estudi (58\%), l'aprofitament el temps (57\%), i per últim, les competències transversals (43\%) que és justament un dels objectius del procés de Bolonya.

Dels set aspectes estudiats, en quatre d'ells (coneixements, metodologies, personals i esforç) els estudiants que entren amb menys nota tendeixen a percebre un progrés una mica més elevat quan se senten més identificats amb la institució. En canvi, en la professionalització i en l'aprofitament del temps són els estudiants que tenen més nota a l'entrar els que experimenten un canvi més notable segons el nivell d'identificació. No hi ha cap diferència pel que fa a les competències transversals entre el conjunt de nota d'entrada més alta i el conjunt dels que la tenen més baixa. En el col-lectiu d'accés a través dels cursos formatius hi ha algunes diferències no significatives, però els percentatges apunten cap a la mateixa direcció. 


\section{Conclusions i discussió}

Les conclusions principals que es deriven d'aquest article són en primer lloc que no hi ha una coincidència total entre les avaluacions acadèmiques i la percepció del progrés en habilitats i coneixements per part dels estudiants. Tot i això, la freqüència del treball de grup influeix positivament en els resultats acadèmics en les tres situacions analitzades.

En segon lloc, el treball de grup, en tant que fa augmentar les relacions entre estudiants i entre estudiants i el professorat, influeix positivament en la integració dels estudiants a la universitat, la qual cosa afecta de manera beneficiosa a la seva autorrealització. Com s'ha fet notar en el text, diversos autors han ressaltat la importància de la integració a la universitat com un mecanisme que afecta a l'aprenentatge dels estudiants i en aquest sentit el treball de grup, amb el pertinent control dels aprofitats, és un bon recurs pedagògic per assolir-ho.

D'aquesta manera, si es vol millorar l'experiència de treball de grup en aquestes universitats cal desenvolupar polítiques que eliminin fins on es pugui les barreres que dificulten la realització d'un bon treball de grup. Això vol dir inicialment, reservar horaris viables perquè els estudiants puguin fer els treballs de grup, reduir el nombre d'estudiants en cada grup de treball, afrontar la formació del professorat en aquesta metodologia i controlar que els grups funcionin de tal manera que augmentin la confiança entre els estudiants, sobretot a partir de resoldre els comportaments dels estudiants que s'aprofiten de la feina dels demés. Cal assolir també que el professorat organitzi unes avaluacions adequades i retorni als estudiants el resultat de les mateixes.

En definitiva, les condicions de manteniment no són les més adequades per portar a terme un treball de grup eficaç i les dades anteriors donen una llista de les possibles prioritats en les polítiques a fer. En realitat, les mancances en les condicions de manteniment bàsiques i de seguretat frustren les expectatives dels estudiants perquè no garanteixen que l'esforç realitzat acabi amb èxit. Quan aquesta frustració és molt forta es poden produir accions de protesta, com ja ha succeït, o d'abandó dels estudis que és un dels problemes que hi ha damunt la taula.

No és difícil d'entendre que una part important del professorat no estigui preparat per orientar els treballs de grup, atesa la tradició de la docència universitària, més aviat orientada a la classe magistral i als apunts de classe, i treballant en un context on l'orientació de tots els incentius de promoció professional han estat vinculats a la recerca.

Cal tenir en compte, també, que en la majoria de titulacions els grups classe són molt nombrosos i les possibilitats de correcció per part del professorat són limitades, la qual cosa es tradueix en l'increment de la mida dels grups de treball, més enllà del què és convenient per realitzar un bon treball, tal com perceben els estudiants mateixos.

Finalment, una de les constatacions d'aquests resultats és la paradoxa que no funcionin igual les notes assolides pels estudiants, que la seva percepció del progrés a la universitat. Quan els estudiants s'identifiquen més amb la institució milloren la percepció dels seus coneixements, habilitats i actituds, però aquesta percepció pot no tenir massa a veure amb els resultats objectius de les qualificacions. Per resoldre aquesta paradoxa la recerca hauria d'avançar en tres direccions: a) Fins a quin punt les metodo- 
logies d'avaluació dels estudiants són les adequades en aquest nou context. b) Fins a quin punt els criteris d'avaluació del professorat $i$, per tant, les notes posades, coincideixen en totes les titulacions. c) Fins a quin punt els estudiants desenvolupen mecanismes de preferències adaptatives, és a dir, «més val pensar que la millora en coneixements i habilitats es produeix, encara que les notes no la recullin».

\section{Referències}

Blau, P. (1964) Exchange and Power in Social Life. New York, Willey.

Creyer, P. i Elton, L. (1990) «Catastrophe theory: a unified model for educational change». Studies in Higher Education, 15-1, p. 75-87.

Darder, P. i Franch, J. (1991) El grup classe. Un potencial educatiu fonamental. Vic, Eumo.

Elias, M.; Masjuan, J.M.; i Sànchez-Gelabert, A. (2012) «Signs of reengagement? Changing in teaching methodology at Spanish universities as a result of the Bologna Process», a Vukasovic, M.; Maassen, P.; Nerland, M.; Pinheiro, R.B; Stensaker, Vabø A. (eds.) Effects of higher education reforms: Change dynamics. Rotterdam, SensePress, p. 21-42.

Elster, J. (2007) Explaining Social Behavior. Cambridge, University Press.

Gigerenzer, G. (2008) Decisiones instintivas. La inteligencia del inconsciente. Barcelona, Ariel.

Hanley, J.; Hartwig, J.; Orbell, J. i Morikawa, T. (2008) «Evolutionary Psychology and more satisfactory model of Human Actiob», a Sullivan B.A. Snyder, M, i Sullivan, J. L. Cooperation. Oxford, Blackwell Publishing, p. 35-52.

Herzberg, F. (1966) Work and the nature of man. Cleveland and New York, The World Publishing Company.

Johnson, D. W. i Johnson, R. (1985) Cooperative Learning: Warms ups. Gouping strategies and Group activities. Edina MN, Interaction Book Company.

Lewin, K. (1952) Teoría del campo en la ciencia social. Barcelona, Paidós.

Lizón, A. (2016) La sociabilidad humana. Estudios de evolución y cognición social. Madrid, Síntesis.

Masjuan, J.M. i Troiano, H. (2009) «Incorporación de España al Espacio Europeo de Educación Superior: El caso de una universidad catalana». Calidad de la Educación, 31, p. 123-142.

Masjuan, J.M i Elias, M. (2012) «The group work: experiences of university Students», a Alain Fernex i Laurent Lima (Eds.) To be Student within the Bologna Process. Grenoble, PUG, p. 67-106.

Masjuan, J.M. (2017) Materials per a repensar la sociologia a partir de Darwin. Barcelona, Octaedro.

Maslow, A.H. (1954) Motivation and Personality. New York, Harper.

Nijstad, B.A. (2009) Group Performance. Hove i New York, Psychology Press.

Prescott, A. i Simpson, E. (2004) «Effective student motivation commences with resolving "dissatisfiers"». Journal of further and higher education, 28 (3), p. 247-259.

Scharpf, F.W. (1997) Games Real Actors. Actor-centered Institucionalism in Policy Research. Oxford, WestviewPress .

Simon, H.A. (2006) Las ciencias de lo artificial. Granada, Comares. 
Troiano, H.; Masjuan, J.M.; Daza, L.; Elias, M. i Sanchez-Gelabert, A. (2012) Los estudiantes ante la nueva reforma universitaria. Informe de resultats. Consultable a (25/11/2016): http://grupsderecerca.uab.cat/gret/sites/grupsderecerca.uab.cat.gret/files/Informe_ complet.pdf

Villar, E. i Font, S. (2007) Guia del pla d'acció tutorial dels estudis de desenvolupament humà a la societat de la informació i psicologia. Girona, Documenta Universitària.

Vroom, V. H. (1964) Work and motivation. San Francisco, CA, Jossey-Bass.

Wilkinson, I. A. G.; Hattie, J. A.; Parr, J. M.; Townsed, M. A. R.; Thrupp, M.; Lauder, H.; i Robinson, T. (1999) Influence of peer effects on learning outcomes: A review of the literature. Final report to the Ministry of Education. Auckland, New Zealand. 


\section{Estudio de los requisitos indispensables para el buen funcionamiento del trabajo en grupo en la universidad}

Resumen: El presente artículo consiste en una revisión de diferentes elementos relacionados con el trabajo en grupo que consiguen que esta metodología sea beneficiosa para el aprendizaje de los estudiantes universitarios. Se lleva a cabo una revisión de la literatura sobre el tema, se presentan los resultados de una investigación cuantitativa basada en los resultados de una encuesta realizada a cerca de 1000 estudiantes de cuatro universidades públicas del Área Metropolitana de Barcelona obtenidos durante el 2010. Se realizan análisis para mostrar la incidencia en el funcionamiento del trabajo en grupo de cada uno de los indicadores que conforman la pirámide de necesidades de Maslow, adaptada al mundo universitario por Prescott i Simpson (2004). Los resultados muestran cómo es necesario llegar a ciertos niveles de calidad en la implementación de esta metodología para que aporte aspectos beneficiosos a los estudiantes universitarios implicados. La reforma de Bolonia, tal y como ha sido implementada, no ha conseguido llegar, en algunas titulaciones, a este nivel mínimo de calidad.

Palabras clave: Trabajo en grupo, Proceso de Bolonia, aprendizaje, cooperación, estudiantes universitarios.

\section{L'étude des conditions nécessaires au bon fonctionnement du travail en groupe à l'université}

Résumé: Cet article passe en revue différents aspects liés au travail en groupe qui bénéficient du point de vue méthodologique à l'apprentissage des étudiants universitaires. Pour ce faire, nous revisitons la littérature sur la question et présentons, en l'occurrence, les résultats d'une recherche quantitative fondée sur les données collectées lors d'une enquête réalisée au cours de l'année 2010 auprès d'un total d'environ 1000 étudiants de quatre universités publiques de l'aire métropolitaine de Barcelone. Des analyses sont effectuées pour montrer l'incidence de chacun des indicateurs de la pyramide des besoins de Maslow, adaptée au monde universitaire par Prescott et Simpson (2004), sur le fonctionnement du travail en groupe. Les résultats montrent la nécessité d'arriver à certains seuils de qualité dans la mise en œuvre de cette méthodologie pour qu'elle puisse bénéficier de quelque manière aux étudiants universitaires concernés. Le processus de Bologne (1999), tel qu'il a été mis en œuvre, n'a pas réussi à atteindre, dans le cas de certains diplômes, ce seuil minimal de qualité.

Mots clés: Travail en groupe, processus de Bologne, apprentissage, coopération, étudiants universitaires.

\section{Study of the essential requirements for group work amongst university students}

Abstract: This article studies the elements that make group work beneficial for university student learning. It reviews the literature on the subject and presents the results of quantitative research based on survey data obtained in 2010 from approximately 1000 students of four public universities in the Barcelona Metropolitan Area. An analysis is made to show how group work is affected by each of the indicators that make up Maslow's hierarchy of needs pyramid, adapted to the university world by Prescott and Simpson (2004). The results demonstrate that for this methodology to be beneficial, its application needs to reach certain quality thresholds. The article also concludes that, in some degree courses, the Bologna Reform (1999) has failed to enable these thresholds.

Keywords: Group work, Bologna Process, learning, cooperation, university students. 